\title{
Pengaruh Pendidikan Kesehatan Dengan Media Video Dan Metode Demonstrasi \\ Terhadap Pengetahuan SADARI
}

\author{
Nurul Aeni ${ }^{1}$, Diyah Sri Yuhandini ${ }^{2}$ \\ ${ }^{1,2)}$ PoliteknikKesehatanTasikmalaya \\ e-mail: tiradiyah@yahoo.co.id
}

\begin{abstract}
Cancer can actually be detected in early stages, including breast cancer that can be done by breast selfexamination (BSE); thus, early treatment can hopefully extend the life expectancy of the patients. Objective to determine the effect of health education conducted with video and demonstration on improving knowledge of BSE among female students of Class XI in SMA Negeri 1 of Sumber in 2018. This quasi experiment used pretest-posttest study design. The samples as the study subjects were collected through purposive sampling technique to 60 female students divided into two groups, demonstration and video group with 30 students in each group. The information was explored using questionnaires. Data analysis used Paired T-test and independent $T$-test.The mean value of knowledge before and after the first group was given video intervention was 65.17 and 76.50, respectively, while the second group was 61.50 and 67.50, respectively. The p-value of knowledge before and after the video and demonstration intervention was $0.00(\geq 0.05)$ and 0.017 $(\leq 0.05)$, respectively. The mean difference of the increased knowledge in both groups showed a p-value of 0.539. The media in form of video and demonstration methods are proven to enbance adolescent knowledge about BSE before and after intervention with no significant difference on increased knowledge between the two groups.
\end{abstract}

Keywords: BSE;demonstration ; health education;knowledge;video

\begin{abstract}
ABSTRAK
Kanker sebenarnya dapat dideteksi pada tahap awal, termasuk kanker payudara yang dapat dilakukan dengan pemeriksaan payudara sendiri (SADARI); Dengan demikian, pengobatan dini diharapkan dapat memperpanjang harapan hidup pasien. Tujuan penelitian untuk mengetahui pengaruh pendidikan kesehatan yang dilakukan dengan video dan demonstrasi pada peningkatan pengetahuan BSE di antara siswa perempuan Kelas XI di SMA Negeri 1 Sumber pada tahun 2018. Percobaan semu ini menggunakan desain penelitian pretest-posttest. Sampel sebagai subyek penelitian dikumpulkan melalui teknik purposive sampling untuk 60 siswa perempuan yang dibagi menjadi dua kelompok, demonstrasi dan kelompok video dengan 30 siswa di masing-masing kelompok. Informasi tersebut dieksplorasi menggunakan kuesioner. Analisis data menggunakan Paired T-test dan independent T-test. Nilai rata-rata pengetahuan sebelum dan sesudah kelompok pertama diberi intervensi video masing-masing adalah 65,17 dan 76,50 sedangkan kelompok kedua masing-masing adalah 61,50 dan 67,50. Media dalam bentuk video dan metode demonstrasi terbukti meningkatkan pengetahuan remaja tentang BSE sebelum dan sesudah intervensi dengan tidak ada perbedaan signifikan pada peningkatan pengetahuan antara kedua kelompok.
\end{abstract}

Kata Kunci : demonstrasi;kankerpayudara;pengetahuan;SADARI;video 


\section{PENDAHULUAN}

Kanker payudara adalah kanker terbanyak kedua di dunia merupakan kanker yang sering terjadi pada perempuan dengan perkiraan 1,67 juta kasus kanker baru yang didiagnosa pada tahun 2012 (25\% dari semua kanker). Diperkirakan pada tahun 2030 insiden kanker mencapai 26 juta orang dan 17 juta diantaranya meninggal. Menurut data World Health Organization (WHO, 2014), insiden kanker meningkat dari 12,7 juta kasus pada tahun 2008 menjadi 14,1 juta kasus pada tahun 2012, sedangkan jumlah kematian meningkat dari 7,6 juta orang pada tahun 2008 menjadi 8,2 juta pada tahun 2012 (WHO, 2014). Berdasarkan estimasi Globocan, International Agency for Research on Cancer (LARC) tahun 2012, insiden kanker payudara sebesar 40 per 100.000 perempuan, kanker leher rahim 17 per 100.000 perempuan, kanker paru 26 per 100.000 laki-laki dan kanker kolorektal 16,6 per 100.000 laki-laki. Insiden kanker serviks 8,2 kematian per 100.000 penduduk. Berdasarkan data sistem informasi Rumah sakit (SIRS) tahun 2010, kasus rawat inap kanker payudara 12.014 kasus (28,7\%), kanker leher rahin 5.349 kasus (12,8\%) (InfoDatin, 2016).
Sedangkan di Propinsi Jawa Barat dengan jumlah penduduk terbanyak di Indonesia yaitu 40.737.594 orang, dimana penduduk wanita sebanyak 49,5\% terdapat angka kejadian tumor/kanker $0,5 \%$ estimasi kejadian 26/100.000 wanita atau sekitar 5200 kasus. Kejadian kanker payudara juga dipengaruhi karena adanya peningkatan angka harapan hidup, gaya hidup yang merugikan kesehatan dan kondisi lingkungan (Suci, 2017).Selain itu menurut laporan tahunan Dinas Kesehatan Kabupaten Cirebon 2016, di Kabupaten Cirebon dengan jumlah penduduk 2.153.560 orang yang mengalami kanker pada tahun 2016 sebanyak 308 kasus dan yang paling tinggi angka kanker yaitu kanker payudara sebanyak 119 kasus $(38 \%)$.

Kanker payudara dapat di deteksi lebih dini dengan cara pemeriksaan payudara sendiri untuk mengetahui stadium awal, sehingga pengobatan dini akan memperpanjang harapan hidup penderita kanker payudara. Pemeriksaan payudara sendiri (SADARI) bisa diterapkan pada remaja putri yang mengalami Perubahan fisik dan perkembangan seks sekunder yaitu masa pubertas mengalami pembesaran payudara terjadi antara usia 
12-13 tahun (Manuaba, Manuaba \& Fajar, 2007). Manfaat pemeriksaan payudara sendiri pada remaja putri untuk mengetahui secara dini adanya tumor atau benjolan pada payudara (Wenny, 2011). Sebaiknya pemeriksaan payudara sendiri dilakukan padasaat menstruasi, yaitu pada hari ke 7-10 dari hari pertama menstruasi dengan pertimbangan pada saat tersebut pengaruh hormon estrogen dan progesteron sangat rendah dan pada saat itu jaringan kelenjar payudara dalam keadaan tidak oedema atau tidak membengkak sehingga lebih mudah meraba adanya tumor atau kelainan (Marmi et al. 2011).

Promosi kesehatan di sekolah ditambah dengan metode promosi yang tepat dalam pelaksanaan dan penerapan merupakan langkah yang strategis dalam meningkatkan derajat kesehatan masyarakat. Hal ini di dasari pemikiran bahwa sekolah merupakan lembaga yang didirikan untuk membina dan meningkatkan kualitas sumber daya manusia baik fisik, mental, maupun spiritual (Pratama ayunda, 2014).

Media promosi kesehatan merupakan salah satu sarana atau upaya yang dapat digunakan untuk menampilkan pesan atau informasi kesehatan yang ingin disampaikan kepada remaja sehingga meningkatkan pengetahuan yang akhirnya diharapkan dapat merubah perilakunya kearah positif atau mendukung terhadap kesehatan. Menurut Edgar Dale bahwa media merupakan integrasi dalam sistem pembelajaran. Namun, efektifitas media tidak dilihat dari seberapa canggihnya media tersebut dalam penggunaanya. Untuk menghindari persepsi yang salah itulah maka terbentuklah media audio visual sebagai media pembelajaran, yang dalam perkembanganya media tersebut memanfaatkan pengalaman yang kongkrit sebagai model peembelajaran. (Devi Sandra Ervina, 2013).

Penggunaan media video dalam kegiatan pembelajaran tidak hanya sekedar sebagai alat bantu, melainkan sebagai pembawa informasi atau pesan yang ingin disampaikan. Penggunaan video tentang SADARI dapat memperjelas gambaran abstrak mengenai pentingnya pemeriksaan payudara sendiri, karena dalam proses pemberianya responden tidak hanya mendengar materi yang sedang disampaikan, tetapi juga melihat secara langsung dan jelas tentang langkahlangkah sadari melalui video tersebut. 
Manfaat penggunaan media audio visual (video) tersebut sesuai konsep pembelajaran menurut piramida pengalaman yang dituliskan oleh Edgar dale, bahwa orang belajar lebih dari $50 \%$ nya adalah dari apa yang telah di lihat dan di dengar (Devi Sandra Ervina, 2013).

Sedangkan pengajaran menggunakan metode demonstrasi adalah untuk memperlihatkan proses terjadinya suatu peristiwa sesuai dengan materi ajar agar siswa dengan mudah untuk memahaminya (Kurniawan, 2015). Metode demonstrasi adalah metode mengajar dengan cara memperagakan barang, kejadian, aturan, dan urutan melakukan suatu kegiatan, baik secara langsung maupun melalui penggunaan media pengajaran yang relevan dengan pokok bahasan atau materi yang sedang disajikan. Metode ini digunakan agar siswa menjadi lebih paham terhadap materi yang dijelaskan karena menggunakan alat peraga dan menggunakan media visualisasi yang dapat membantu siswa untuk lebih memahami.(Rohendi Dedi, et al. 2010)

Penelitian ini sesuai dengan yang dilakukan oleh Ervina Sandra Devi dan Warsitipada (2013) menunjukkan bahwa ada media audio visual yang mempengaruhi perpanjangan video ke tingkat knowlegde sadar. Tingkat pengetahuan sebelum panduan masuk kategori kurang $(53,3 \%)$ dan meningkat ke kategori cukup $(46,7 \%)$ setelah diberi konseling dengan video media audiovisual. (Devi Sandra Ervina, 2013).Penelitian Rizka Angraini (2017) menunjukkan mayoritas siswi berpengetahuan kurang sebanyak $31(62 \%)$ responden, terdapat hubungan antara pengetahuan dengan SADARI dan terdapat hubungan antara sikap dengan SADARI.

Berdasarkan studi pendahuluan yang dilakukan pada tanggal 27 Desember 2017, telah dilakukan wawancara kepada 10 siswi kelas XI didapatkan hasil dari 10 siswi ternyata pengetahuan tentang SADARI sangatlah kurang 8 orang diantaranya tidak mengetahui sama sekali apa itu SADARI sedangkan 2 orang lainnya sudah mengetahui tetapi tidak pernah melakukannya. Selain itu mereka belum mendapatkan informasi baik dari instansi kesehatan maupun dari sekolah itu sendiri, begitu pula belum ada yang melakukan penelitian mengenai SADARI itu sendiri. 


\section{METODE PENELITIAN}

Penelitian ini menggunakan desain penelitian quasi experiment. Rancangan penelitian menggunakan pre-post control design. Pengambilan sampel menggunakan teknik Purposive sampling, setelah itu dilakukan random sampling untuk menentukan sampel. Pengumpulan data menggunakan kuesioner sebagai pre-test. Kelompok experimen diberikan intervensi video dan kelompok kontrol diberikan demonstrasi,dilanjutkan post test. Analisis data menggunakan paired t-test. Penelitian ini dilaksanakan pada bulan Desember2017 sampai bulan April 2018 di SMA Negeri 1 Sumber Kabupaten Cirebon. Populasi adalah seluruh siswi kelas XI SMA Negeri 1 Sumber Kabupaten Cirebon yang hadir dan bersedia menjadi responden, siswi yang sudah rutin melakukan SADARI sebanyak 200 orang, dengan sampel 23 orang.Mengantisifasi drop out, sehingga jumlah sampel di dapatkan 25 orang dan peneliti menambahkan 10 orang agar sampel lebih banyak. Sehingga masingmasing kelompok berjumlah 30 orang.

Terdapat dua kelompok yaitu kelompok intervensi video dengan muatan konsep langkah-langkah tentang SADARI dengan karakteristik remaja umur 15-17 tahun, dan kelompok intervensi demonstrasi tentang langkah-langkah SADARI. Waktu untuk penayangan video dan pelaksanaan demonstrasi kepada responden yaitu selama 15 menit, kemudian diberikan jeda selama 30 menit, kemudian diuji kembali dengan koesioner pengetahuan yang sama.

Instrumen berupa kuesioner pengetahuan SADARI yang di modifikasi oleh Pratama Ayunda dengan nilai uji validitas dan reabilitas Chronbach Alpha (0,979). Video merupakan instrumen yang digunakan sebagai intervensi yang diberikan pada kelompok ekperimen sedangkan demonstrasi menggunakan instrument Phantom payudara dengan menggunakan Standar Operasional Prosedur (SOP) untuk kelompok kontrol. Analisis data menggunakan paired T-test untuk melihat perbedaan skor sebelum dan sesudah antara kelompok video dan demonstrasi. Perhitungan statistik untuk analisa tersebut dengan menggunakan program komputerisasi dengan SPSS versi 18.

\section{HASIL}

Hasil analisis di dapatkan rata-rata pengetahuan remaja putri tentang SADARI sebelum di berikan intervensi pada kelompok hasil rata-rata video pengetahuan remaja putri SADARI 
sebelum diberikan intervensi pada kelempok video adalah 65,17. Nilai terendah 25 dan nilai tertinggi 95. Nilai median nya 65,00 dengan standar deviasi 14,293. Hasil 95\% confidence interval (CI)dapat disimpulkan bahwa 90\% pengetahuan remaja putri di SMAN 1 Sumber tentang SADARI diantara 59,83 sampai 70,50 dan setelah diberikan intervensi video adalah 76,50 dengan nilai terendah nya 65 dan nilai tertinggi 95 . Nilai median 75,00 dengan standar deviasi 8,320. Hasil 95\% confidence interval (CI)dapat disimpulkan bahwa 95\% pengetahuan remaja putri di SMAN 1 Sumber tentang SADARI diantara 73,39 sampai 79,61.

Tabel 1. Distribusi pre test dan post test PengetahuanResponden

\begin{tabular}{lcccccccc}
\hline & $\mathrm{N}$ & Min & Max & Mean & SD & Median & $95 \%$ CI & $\begin{array}{l}\text { Nilai } \\
\text { total }\end{array}$ \\
\hline $\begin{array}{l}\text { Pre test } \\
\text { demonstrasi }\end{array}$ & 30 & 45 & 80 & 61,50 & 10,517 & 60,00 & $57,57-65,43$ & 20 \\
\hline $\begin{array}{l}\text { Post } \\
\text { testdemonstrasi }\end{array}$ & 30 & 45 & 85 & 67,33 & 12,229 & 67,50 & $62,77-71,90$ & 20 \\
\hline Pre test video & 30 & 25 & 90 & 65,17 & 14,293 & 65,00 & $59,83-70,50$ & 20 \\
\hline Post test video & 30 & 65 & 95 & 76,50 & 8,320 & 75,00 & $73,39-79,61$ & 20 \\
\hline
\end{tabular}

Tabel 2. Distribusi Normalitas Skewness dibagi Standar eror

\begin{tabular}{llll}
\hline Data yang di uji & Skewness & StandarEror & Distribusi \\
\hline Pre testdemonstrasi & 0.193 & 0,427 & Normal \\
\hline Post testdemonstrasi & $-0,313$ & 0,427 & Normal \\
\hline Pre test video & $-0,729$ & 0,427 & Normal \\
\hline Post test video & 0,304 & 0,427 & Normal \\
\hline
\end{tabular}

Kemudian demonstrasi adalah 61,50. Nilai terendah 45 dan nilai tertinggi dari nilai total 20 pertanyaan. Nilai median 60.00 dengan standar deviasi 10,517. Hasil $95 \%$ confidence interval (CI) dapat di simpulkan bahwa 95\% di yakini pengetahuan remaja putri di SMAN 1 Sumber tentang SADARI di antara 57,57 sampai 65,43. Setelah diberikan intervensi demonstrasi adalah 67,50 dengan nilai terendah 45 dan tertinggi 85 . Nilai median 67,50 dan standar deviasi 12,229. Hasil $95 \%$ confidence interval (CI) dapat disimpulkan bahwa 95\% diyakini pengetahuan remaja putri di SMAN 1 
Sumber tentang SADARI diantara 62,77 sampai 71,90.

Tabel 2 telihat perhitungan hasil statistik menggunakan SPSS. Di ketahui pengujian normalitas data menggunakan cara bahwa nilai Skewness / Standar eror menghasilkan angka padapre test video -0,729/0,427= 1,707 ( $\leq 2)$ dan angka post test video $0,304 / 0,427=0,712(\leq 2)$ sedangkan angka pre test demonstrasi adalah $0,193 / 0,427=0,452(\leq 2)$, angka post test demonstrasi $-0,313 / 0,427=-0,733(\leq 2)$ dari hasil bagi di atas sehingga dapat di simpulkan bahwa distribusinya normal.
Oleh karena itu pengolahan data menggunakan uji t bisa di laksanakan.

Tabel 3 diperoleh hasil nilai P-V alue video sebesar 0,000 dan P-value demonstrasi sebesar 0,017. Hal ini menunjukan bahwa nilai P-value $\leq 0,05$ artinya dapat disimpulkan bahwa terdapat pengaruh peningkatan pengetahuan dengan menggunakan media video dan metode demonstrasi sebelum dan sesudah intervensi terhadap pengetahuan remaja tentang SADARI, sehingga keduanya efektif.

Tabel 3. Distribusi Paired T-test pada kelompok Video dan Demonstrasi

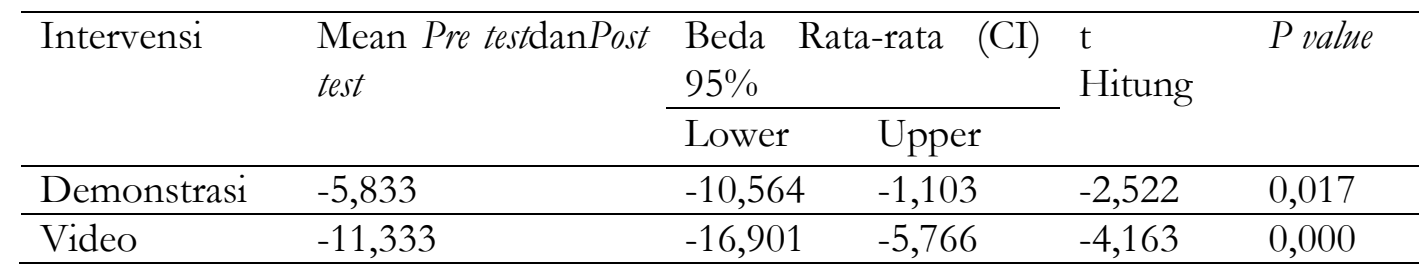

Tabel 4. Distribusi data darianalisis independent T-test

\begin{tabular}{lllll}
\hline $\begin{array}{l}\text { Analisis independent T- test } \\
\text { perubahanskorpengetahuan }\end{array}$ & $\begin{array}{l}\text { Rata-rata } \\
(\mathrm{SD})\end{array}$ & $\begin{array}{l}\text { Beda rata- } \\
\text { rata (SD) }\end{array}$ & P5 CI & $\mathrm{P}$ \\
\hline Demonstrasi & 10,83 & $-1,833$ & $(-7.766-4.099)$ & 0,539 \\
\hline Video & 12,67 & $-1,833$ & $(-7.790-4.123)$ & 0,539 \\
\hline
\end{tabular}

Tabel 4 menunjukan perubahan dilihat untuk kelompok video sebesar responden pada pre test dan post test dapat 12,67 sedangkan demonstrasi sebesar 
10,83. Beda rata-rata antara kedua kelompok sebesar -1,833 dengan nilai $\mathrm{p}$ value $0,539 \geq 0,05$ dapat di simpulkan bahwa tidak terdapat perbedaan yang signifikan pada nilai perubahan skor pengetahuan responden pada kelompok video dan demonstrasi.

\section{PEMBAHASAN}

\section{Pengetahuan remaja SADARI}

Tingkat pengetahuan siswi SMAN 1 Sumber sebelum diberikan intervensi demonstrasi memiliki pengetahuan yang cukup setelah diberikan intervensi demonstrasi dapat dikatakan baik karena mengalami kenaikan pengetahuan. Sedangkan pengetahuan siswi SMAN 1 Sumber sebelum di berikan intervensi video memiliki pengetahuan yang cukup dan setelah di berikan intervensi video mengalami kenaikan pengetahuan yang sangat tinggi.

Karakteristik siswi yang di teliti yaitu siswi kelas XI yang memang sudah mendapatkan materi tentang kesehatan reproduksi di mata pelajaran biologi dasar sehingga pengetahuan mereka sudah cukup baik ketika diberikan intervensi tentang SADARI. Hasil penelitian tersebut sejalan dengan penelitian Diah Lestrasi Dwi \& astuti, (2017) menunjukan bahwa terjadi peningkatan pengetahuan sebelum dan sesudah diberikan.Sejalan pula dengan Mubarak, (2009). menyatakan bahwa semakin tinggi pendidikan seseorang semakin mudah pula mereka menerima informasi sehingga akan semakin banyak pengetahuan yang dimilikinya. Pendidikan memiliki peran dalam proses pengembangan diri manusia, sehingga erat kaitannya dengan reaksi serta pembuatan keputusan terhadap sesuatu hal.

Pengetahuan adalah hasil pengindraan manusia, atau hasil tahu manusia melalui indra yang dimilikinya baik mata, hidung, telinga dan sebagainya. Proses munculnya pengetahuan dari pengindraan sangat dipengaruhi oleh indra pendengaran dan indra penglihatan. Pengetahuan dipengaruhi oleh beberapa faktor yaitu : pengalaman, pendidikan, instruksi verbal, dan penerimaan informasi verbal dari pihak lain, pekerjaan, umur, informasi dan media (Notoatmodjo S, 2007).

\section{Perbedaan pengetahuan sebelum dan sesudah intervensi}

Berdasarkan hasil penelitian ini menunjukan perbedaan pengetahuan sebelum dan sesudah diberikan intervensi 
antara kedua kelompok yaitu kelompok demonstrasi dengan beda mean antara 10,564 sampai - 1,103 dan kelompok video antara -16,901 sampai -5,766. Dapat disimpulkan bahwa kelompok video mengalami kenaikan sedikit berbeda dibandingkan kelompok demonstrasi meskipun kedua kelompok mengalami kenaikan skor.Selanjutnya untuk mengetahui pengaruh terhadap pemberian pendidikan kesehatan dengan menggunakan metode demonstrasi dan media video terhadap tingkat pengetahuan SADARI (pemeriksaan payudara sendiri) pada remaja putri kelas XI SMAN 1 Sumber tahun 2018 dapat dilihat dari hasil uji analisis. Hasil uji paired t-test diperoleh t hitung demonstrasi sebesar -2,522 dengan nilai $\mathrm{p}=0.017$ dan $\mathrm{t}$ hitung video sebesar -4,163 dengan nilai $\mathrm{p}=0,000$. Dengan melihat nilai $\mathrm{p}<0,05(0,001$ dan $0.000<0,05)$ sehingga dapat dinyatakan terdapat pengaruh yang signifikan pemberian pendidikan kesehatan dengan menggunakan media video dan metode demonstrasi terhadap tingkat pengetahuan SADARI.

Hasil yang didapatkan dari penelitian ini sejalan dengan penelitian yang dilakukan oleh Sulastri, (2012) di SMAN 9 Balik Papan menyatakan bahwa penyuluhan kesehatan pemeriksaan SADARI dengan media video dapat meningkatkan pengetahuan remaja putri. Penelitian ini juga sebanding dengan penelitian Shorea, dkk, (2011) di SMAN 2 Pekanbaru menyatakan bahwa media video dapat meningkatkan sistem pembelajaran siswa tentang SADARI sehingga siswi mengetahui cara langkah-langkah pemeriksaan payudara senidri (SADARI).

Penelitian ini meningkatkan pendidikan kesehatan tentang kesehatan reproduksi khususnya kesehatan payudara seorang remaja putri SMAN 1 Sumber. Pengetahuan tentang pemeriksaan payudara sendiri (SADARI) sangat penting diketahui dan dipahami oleh seorang remaja puri. Menurut (Munadi,2012), Menggunakan media video mempunyai dampak yang lebih pada penyuluhan kesehatan yaitu mengandalkan pendengaran dan penglihatan dari sasaran, menarik, pesan yang disampaikan cepat dan mudah diingat dan dapat mengembangkan pikiran dan mengembangkan imajinasi remaja putri. Hal ini sejalan dengan Notoatmodjo, (2010) bahwa Penyuluhan kesehatan dengan video pada remaja putri SMAN 1 Sumber Kab Cirebon dapat memperjelas gambar- gambar dan 
langkah-langkah pentingnya pemeriksaan SADARI, karena dalam proses pemberiannya responden tidak hanya mendengar suara tetapi responden akan melihat secara langsung dan jelas langkahlangkah pemeriksaan payudara sendiri (SADARI). Suparmi (2014) berpendapat bahwa metode demonstrasi bisa meningkatkan motivasi dalam praktik SADARI.

Metode demonstrasi adalah penyajian dengan menunjukan urutan prosedur pembuatan sesuatu atau proses terjadinya sesuatu untuk mencapai tujuan pengajaran. Beberapa keuntungan dari penggunaan metode demonstrasi yaitu metode ini dapat memberikan suatu keterampilan tertentu kepada kelompok sasaran, lebih menarik dan lebih mudah dalam memahami sesuatu, perhatian siswa lebih terpusat kan pada pelajaran yang sedang diberikan, kesalahan-kesalahan yang terjadi bila pelajaran itu diceramahkan dapan diatasi melalui pengamatan dan contoh yang nyata. Metode demonstrasi dan penggunaan media video tentang SADARI akan meningkatkan pengetahuan yang berbeda dengan metode penggunaan media pembelajaran dalam bentuk visual, seperti leaflet, karena pada tahap ini responden hanya akan membaca secara verbal tanpa melihat langkah SADARI secara jelas dan konkrit. Selain itu menurut Edgar Dale bahwa pengalaman membaca secara verbal hanya akan memberikan pengetahuan $10 \%$ dari apa yang telah didapatkan.

\section{Perbedaan kenaikan rata-rata pengetahuan pada kelompok video dan demonstrasi.}

Dari pengujian independent T-test yang dilakukan kelompok demonstrasi dan kelompok video dapat disimpulkan tidak terdapat perbedaan yang bermakna antara kedua kelompok. Berdasarkan hasil di atas menunjukan demonstrasi dan video keduanya efektif. Sesuai Milwati, Susi. et al. (2015) menyatakan bahwa hasil penelitian setelah dilakukan pendidikan kesehatan diperoleh bahwa kemampuan ibu melakukan SADARI mengalami peningkatan hal ini ditunjukan dengan hasil uji beda dimana ada perbedaan kemampuan melakukan SADARI sebelum dan sesudah pendidikan sadari, dimana nilai signifikansi $<0.05$ yang artinya ada peningkatan kemampuan melakukan SADARI setelah dilakukan pendidikan kesehatan melalui metode demonstrasi sehingga pendidikan 
kesehatan terhadap kemampuan melakukan SADARI menjadi efektif. Syah (2005), bahwa metode demonstrasi adalah metode mengajar dengan cara memperagakan barang, kejadian, aturan, dan urutan melakukan suatu kegiatan, baik secara langsung maupun menggunakan penggunaan media pengajaran yang relevan dengan pokok bahasan atau materi yang disajikan.Dalam metode demonstrasi pendidik dapat membimbing peserta didik kearah berfikir yang sama dalam satu saluran pikiran yang sama sehingga dapat mengurangi kesalahan-kesalahan bila dibandingkan hanya dengan membaca atau mendengarkan karena peserta didik mendapatkan gambaran yang jelas dari hasil pengamatannya.

Pemberian penyuluhan dilakukan agar dapat meningkatkan pengetahuan responden tentang SADARI karena di dalam penyuluhan diberikan materi tentang SADARI yang dikemas dalam bentuk video yang menarik, dan diperagakan dengan dilakukan demonstrasi, sehingga responden secara langsung dapat memperoleh informasi. Selain itu pada proses penyuluhan juga diadakanya jawab sehingga bagi responden yang belum memahami materi tentang SADARI dapat langsung mengajukan pertanyaan dan informasi dapat dipahami secara baik oleh responden.

Media video dan metode demonstrasi dapat meningkatkan pengetahuan tentang SADARI. Hasil uji keefektivitasan video dan demonstrasi dengan melihat perbandingkan antara dua kelompok, ternyata kedua kelompok antara video dan demonstrasi tidak terdapat kenaikan yang signifikan. Kemungkinan dikarenakan pada saat pengambilan data kondisi responden kurang kondusif dikarenakan waktu pengambilan data yang diberikan oleh pihak sekolah pada jam 10.30 WIB, sehingga responden mengerjakan tahapan penelitian dengan terburu-buru. Akan lebih maksimal jika pengambilan data dilakukan pada pagi hari dan diberikan waktu seharian full. Maka dapat disimpulkan bahwa media video dan metode demonstasi keduanya berpengaruh untuk meningkatkan pengetahuan remaja terhadap SADARI..

\section{KESIMPULAN}

1. Pengetahuan remaja sebelum diberikan intervensi dan setelah 
diberikan intervensi berupa video dan demonstrasi pengetahuan remaja mengalami peningkatan menjadi lebih baik.

2. Terdapat pengaruh peningkatan pengetahuan dengan menggunakan media video dan metode demonstrasi sebelum dan sesudah intervensi.

Tidak terdapat perbedaan yang bermakna kenaikan rata-rata pada kelompok video dan demonstrasi. Direkomendasikan bagi sekolah untuk terus meningkatkan kerjasama dengan pihak puskesmas atau tenaga kesehatan dalam mengadakan penyuluhan pendidikan kesehatan tentang kesehatan dan kesehatan reproduksi bagi siswi khususnya tentang kesehatan payudara. Untuk peneliti selanjutnya di harapkan dapat menambahkan hal menarik pada saat melakukan demonstrasi agar responden tidak merasa monoton dan membosankan, selain itu juga penambahan jumlah dan variabel.

\section{REFERENSI}

Diah, L.D., \& Astuti. (2017). EfektivitasPenyuluban Pemeriksaan Payudara Sendiri Dengan Media Video dan Phantom terhadap Praktik. $S A D A R I$ pada siswi SMPN 1 Nanggulan.Universitas 'Aisyiyah Yogyakarta. Tersedia di portal garuda, Online diunduh tanggal 25 Oktober 2017.
Ervina, D.S.,\& Warsiti. (2013). Pengaruh penyuluban media audio visual video terhadap tingkat pengetahuan pemeriksaan payudara sendiri (SADARI) pada kader posyandu di tejokusuman $\mathrm{Rw}$ 04 notoprajan yogyakarta tahun 2013. STIKES Aisyiyah Yogyakarta.

Huda, M. (2016). Pembelajaran Berbasis multimedia Dan pembelajaran Konvensional, 10(1), 125-146.

Kurniawan, N. (2015). Penerapan Metode Demonstrasi Pada Mata Pelajaran Kearsipan Guna Meningkatkan Prestasi Belajar Siswa Kelas X Kompetensi Keablian Administrasi Perkantoran SMK YPE Sawunggalih Kutoarjo. Univrsitas Negeri Yogyakarta Tersedia di e-jurnal, Online diunduh tanggal 25 Oktober 2017.Manuaba, I.B.G., I.A. Chandranita Manuaba, dan I.B.G. Fajar Manuaba,. (2007). Pengantar Kuliah Obsetri. Jakarta: Buku Kedokteran EGC,

Melina Fitria, Soebiyanto, A., \& Wujoso, H. (2014). Perbedaan Media Pembelajaran (Leaflet Dan Video ) Terhadap Keterampilan Sadari Ditinjau Dari Motivasi. Jurnal Ilmu Kesehatan, Tersedia di portal garuda, Online diunduh tanggal 25 Oktober 2017

Milwati, Susi. et al. (2015). Penerapan Promosi Kesehatan Metode Demonstrasi dan Keterampilan Pemeriksaan Payudara Sendiri (S AD ARI)Bagi Ibu-ibu PKK di Kota Malang.Malang: Poltekkes Kemenkes Malang.Tersedia di portal garuda, Online diunduh tanggal 25 Oktober 2017

Mubarak, WI. (2009). Imu Kesehatan Teori dan Aplikasi. Jakarta: Salemba Medika

Munadi, Y. (2012). Media Pembelajaran: 
Sebuan Pendekatan Baru. Jakarta: Gaung Persada Press.

Nisman, W. A. (2011). lima menit kenali payudara. Yogyakarta: C.V ANDI OFFSET.

Rohendi Dedi, et al. (2010). Efektivitas Metode Pembelajaran Demonstrasi Terhadap Peningkatan Hasil Belajar Siswa Kelas X Pada Mata Pelajaran Keterampilan Komputer dan Pengelolaan Informasi Di Sekolah Menengah Kejuruan. Jurnal Pendidikan Informasi Dan Komunikasi, 3(1), 16-18. Tersedia di portal garuda, Online diunduh tanggal 25 Oktober 2017

Shorea, R., Agrina., Rismadefi, W. (2011). Efektifitas Promosi Kesehatan Melalui Audio Visual Tentang Pemeriksaan Payudara Sendiri (SADARI) Terbadap Peningkatan Pengetahuan pada remaja putri di SMAN 2. Jurnal. Riau: Universitas Riau. Tersedia di portal garuda, Online diunduh tanggal 15 April 2018.

Suci, W. F. dan A. M. (2017). HubunganTingkat Pengetahuan Dan Sikap Dengan Perilaku Pemeriksaan Payudara Sendiri (SADARI). universitas Ahmad Dahlan Yogyakarta. Tersedia di portal garuda, Online diunduh tanggal 30 Oktober 2017

Sulastri, et al. (2012). Pengarub Penyuluban Kesehatan Menggunakan Video Dalam Pemeriksaan Payudara Sendiri
(SADARI) terbadap PerubahanPengetabuan dan Sikap Remaja Putri Di SMAN 9 Balikpapan. Kalimantan Timur: Jurnal Promosi Kesehatan Nusantara Indonesia Tersedia di portal garuda, Online diunduh tanggal 15 April 2018.

Suparmi, Winarni. (2014). Peningkatan Motivasi Deteksi Dini Kanker Payudara dengan Pendidikan Kesehatan metode Demonstrasi. Proceeding Simposium Nasional 2016. Fakultas Kedokteran UNS. Tersedia di ejurnal, Online diunduh tanggal 15 April 2018.

Syah, M. (2005). Psikologi Pendidikan Suatu Pendekatan Baru. Bandung : Rosda karya.

Pratama Ayunda, I. (2014) Efektifitas Pendidikan Kesehatan terhadap Nilai Pengetahuan Mengenai Pemeriksaan Payudara Sendiri (SADARI) pada remaja putri di SMPN Tangerang Selatan. Ilmu Keperawatan, Fakultas Kedokteran dan Ilmu Kesehatan universitas Islam Negeri Syarif Hidayatullah Jakarta. Tersedia di portal garuda, Online diunduh tanggal 25 Oktober 2017 